\title{
miniLABs - Focused Lab Sessions in Manufacturing Technology Related to Forming Processes
}

\author{
(a work in progress) \\ http://dx.doi.org/10.3991/ijep.v3iS3.2780
}

\author{
C. Pleul, A. Sadiki, M. Hermes, S. Chatti and A. E. Tekkaya \\ TU Dortmund University, Dortmund, Germany
}

\begin{abstract}
Laboratory experiments play a significant role in engineering education. The main concern of the described hands-on miniLABs initiative (as a work in progress) is lowering the hurdles in order to provide engineering students with an informal and straightforward access to experiments carried out in labs of the IUL at TU Dortmund University. miniLABs will offer students different, short and voluntary hands-on lab sessions, consisting of two different modes and different aspects related to manufacturing technology in the field of forming processes. In small teams, students can get in touch with practical engineering activities in the fields of present scientific research, either to study a certain phenomenon or to look at a wider engineering context. Based on the framework of experiential learning, miniLABs tries to foster the shift from teaching to deep learning. Finally, this initiative aims to inspire young students for real and hands-on engineering experiments and to contribute to the science education of these young and future engineers.
\end{abstract}

Keywords-engineering education; manufacturing technology; forming; experiments; laboratory learning

\section{INTRODUCTION}

Engineering seen as a method consists by itself of experimentation [1]. Interesting examples of this aspect are impressively shown when looking at the procedures and methodologies used for scientific investigation, e.g. for the identification of relevant material properties for a modern forming process [2] or the development of an innovative manufacturing process such as the $3 \mathrm{D}$ profile bending processes [3], [4]. In addition to other factors, laboratory work in engineering education is therefore seen as a very important part [5-13].

Working along the different stages of a lab course, like the individual preparation of the subject, discussing and getting feedback on the collected basics, planning the experimental procedure and carrying out the experiment itself, finishing it with the data analysis and the application to the engineering subject, students can take advantage of the opportunity to develop necessary competencies [14]. This process can consist of engineering competencies related to professional as well as to individual and social aspects. Therefore, using the experiment as a scientific and practical tool during lab sessions in small

${ }^{\dagger}$ The invited contribution is based on an awarded submission to the IEEE Global Engineering Education 2013 conference. groups, students get in touch with an environment of relevant technologies, machines and methods as well as further engineering skills like team work or with situations where they need to clearly express themselves as part of engineering communication [15], [16].

Therefore, carrying out lab courses at different levels of learning and different degrees of complexity can foster the link between theoretical representations of engineering phenomena and practical applications. Furthermore, this can enhance the conceptual understanding of the subject dealt with including aspects of critical thinking. This is an important factor, which employers of different fields ask for when talking to young professionals [17].

\section{MAIN GOALS OF HANDS-ON MINILABS}

Although importance of laboratory work in engineering education is obvious [18], [19], students often do not have the opportunity to get to know the experimental facilities and the usage in a certain department of their choice. Furthermore, often there is also no obvious hands-on access to the field of application of this equipment and its engineering questions and scientific requirements behind it. Taking these aspects into account the following main goals of miniLABs are

- to provide an informal, straightforward and guided access to simple and comprehensive test equipment in general,

- to provide the opportunity to focus on the experiment as a scientific tool itself to investigate a certain phenomenon (mode 1 ) or

- to deal with a wider context of some engineering problem (mode 2) where the experiment plays a key role and

- to compose the different aspects of the subject dealt with to get an idea of relevant and applied practices in the context of scientific engineering research when using experimentation.

\section{A. Informal and straightforward access}

For the planned miniLABs there is no need for the student to fulfill a special precondition in order to attend. Every engineering student that is interested to get to know more of an engineering activity or some of the provided test equipment is kindly welcome. Even students taking their first steps in this direction will be adequately coached. In this regard, coaching means an appropriate 
guidance to help students reaching a higher level of understanding of the subject of the hands-on miniLAB.

\section{B. Phenomena and wider context}

For the first phase, the planned miniLABs will provide two different hands-on approaches - mode 1 (phenomena) and 2 (wider engineering context).

Mode 1 means students have the opportunity to focus explicitly on an experiment in detail, e.g. an extrusion test. This comprises the consideration of the experimental preconditions, like an overview of what needs to be set-up and configured and in which way. And the experimental hands-on procedure by itself and how it is methodologically planned and carried out by incorporating the relevant dependent (measured) variables and how they are affected by modifying the corresponding independent (correcting) variables in order to study a certain phenomenon. Afterwards, mode 1 consists of the appropriate analysis of the experimental data. Furthermore, the students get in touch with the experimental equipment (machines, tools, etc.) and learn more about the procedure. Finally, the quality of the experiment and the acquired data will be discussed.

In mode 2, students can decide to deal with the experiment in a wider context. Then, a presently relevant engineering problem is provided. Here, the hands-on experiment still plays a key role but further aspects are taken into account. This spans from using the test data within a following context e.g. to simulate a certain material behavior (to appropriate the design of a machine component) or to adjust certain process parameters e.g. to produce a part for an innovative space frame in the automotive industry that consists of bent components.

To support a better understanding of an adequate use of the experiment as a scientific tool in engineering research, the meaning of

- using an approximating model in contrast to measuring real data for describing a behavior (cp. [20]) as well as

- the basic criteria for good test quality, such as objectivity, reliability and validity,

are considered in both modes. As part of students' science education, these aspects will contribute to support a basic level of epistemological understanding.

\section{Composition of different aspects}

Both, the focus on the experiment in detail to study a certain phenomenon and the approach in a wider engineering context will be justified according to its relevance for engineering practices. This is seen as a relevant objective to support the continuous development process of a sound picture of a professional engineer.

\section{DIDACTICAL FRAMEWORK}

Even if the lab sessions are short - that's why we unsurprisingly call them miniLABs - the concept will be based on a framework that is intended to suit the key requirements for learning in the lab - actively doing something on your own in a small team. Therefore, this framework will be based on applied experiential learning and active student centered learning based on the shift from teaching to learning as well as the alignment of intended learning outcomes, learning activities and feedback.

\section{A. Experiential learning}

According to Kolb, learning is defined as "the process whereby knowledge is created through the transformation of experience. Knowledge results from the combination of grasping and transforming experience" [21].

In detail, this "experiential learning theory" consists of four consecutive steps forming a closed cycle that in turn serves as the first round of an evolving spiral during the learning process. Starting the cycle with a concrete or immediate experience, which forms the basis for the following steps, means being involved in a certain situation in order to experience something. This is followed by observation and reflections, by which the experience is examined, and, afterwards, the formation of abstract concepts focusing on the generalization in order to, for example develop theories on why an event took place the way it did. The following stage of the cycle consists of active experimentation, during which the impact of new concepts is tested. This serves as the basis for new concrete experiences, on the next round of the spiral. [22] During an entire loop of the experiential learning cycle as described above, the student will get in contact with all the essential activities such as experiencing, reflecting, thinking, and acting [23].

For miniLABs, this transformation of experience in order to construct knowledge is seen as an active process that is influenced by social interactions, which need to be considered in the conceptualization, especially when using the experiential learning cycle as one pillar for the framework of the miniLABs.

\section{B. Shift from teaching to learning and learning by guiding}

For miniLABs, the well-known and often discussed approach to move from teaching to learning will become very obvious. As described, the format will comprise small lab sessions to get students in touch with relevant equipment and methods and procedures behind it. Therefore, the labs will not be able to mainly focus on the content but much more on the outcome and the process to achieve it. This is mainly inherent to the format and will be characterized by a student-centered approach, where students and their activities will be in the center of learning. As much as possible within the miniLABs format, the centering of students and their learning processes will be considered as a design principle [24], [25]. Consequently, this can only be achieved by changing the role of the teacher, away from instruction-centered to more acting as a coach that provides appropriate guidance through the learning environment - the lab in that case. Additionally, this approach is supported by the active integration of experienced student assistants as mentors. They will be trained in advance to be able to guide attending students through the miniLAB. Hence, the entire learning process of both the attending students and the mentors will be more and more active and geared to the intended learning outcomes of

- getting to know relevant equipment and methods and procedures in their field and

- experience the relevance of carrying out experiments scientifically as an essential tool for engineers. 


\section{Constructive alignment and lab objectives}

Since miniLABs will not consist of any kind of assessment, it still will be a design principle to reach the highest possible level of alignment as described in [26]. Therefore, the intended learning outcomes will follow the objectives and will be attuned to the applicable aspects of the fundamental laboratory learning objectives of Feisel and Rosa [27]. Following Feisel and Rosa, these objectives consist of 13 aspects formulated as a resulting ability through the lab experience by the students. This can mean for example to plan an experimental approach and apply the appropriate instrumentation (e.g. sensors or software) and manipulate it, identifying strengths and limitations of theoretical models of real world phenomena and critically analyze the data acquired by the experiment in order to objectively communicate the findings.

These aspects span over several domains including the cognitive, the psychomotor and the affective one. For the miniLABs, it is intended to consider all three domains equally important in every setup, subject and mode, even though on different levels of occurrence.

Considering the objectives of laboratory learning as part of the intended learning outcomes, the planned lab activities need to be aligned in order to support students in reaching the learning outcomes. Finally the students' feedback and exchange of experiences in the team can be seen as the closing event for a miniLAB session.

\section{PREPARATION FOR PUTTING INTO PRACTICE}

In accordance with the mentioned objectives, the handson miniLABs need to be structured to provide the opportunities to just drop in and become fascinated by the experimental work engineers do.

\section{A. Chosing a subject and a mode}

All relevant information necessary to select and join the most appropriate miniLAB will be available on a web site. Figure 2 shows the page, which is still under construction. Students can select either mode 1 (left) with the focus on the explicit phenomenon or mode 2 with a wider engineering context. As an example, the following Figure 2 shows the description of the miniLAB in mode 2 for material characterization.

\section{B. An example - material characterization in mode 2}

In engineering the experiments for material characterization are used to discover a material behavior by collecting certain test data. One of these experiments can be a hardness test or a uniaxial tensile test, which has a very straightforward principal. A geometrically defined specimen is fixed at its ends and loaded with, for example a continually increasing force on one end. Under this increasing force, the specimen changes its geometric dimensions. Special sensors measure those changes in length and width. Figure 3 shows the part of the set-up procedure by a student where the specimen is precisely placed between the clamping units and sensors.

Simultaneously with the experiment, the derived data are collected with measurement software and plotted on a real time diagram as exemplified in Figure 4.

Knowing the initial dimensions of the specimen and the behavior under the increasing load, characteristic material parameters can be calculated and used for further engineering design or for simulation of the material. For

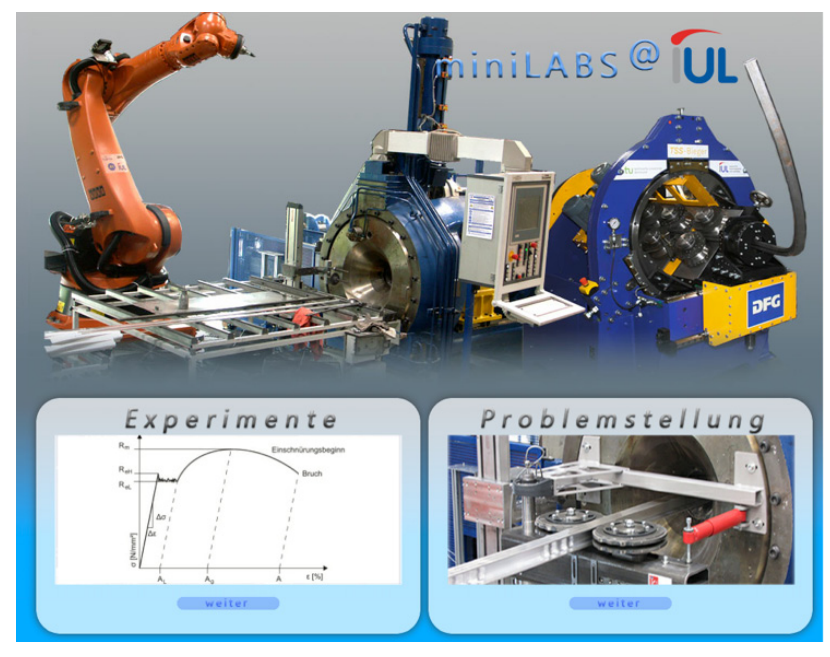

Figure 1. Present design of the miniLABs site

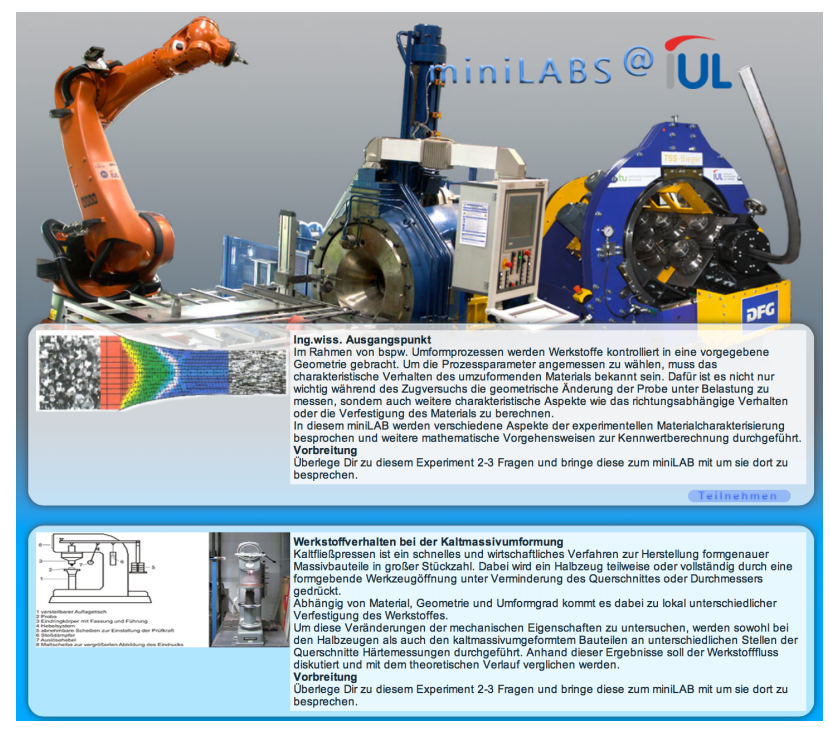

Figure 2. miniLAB for material characterization in mode 2 (wider context)

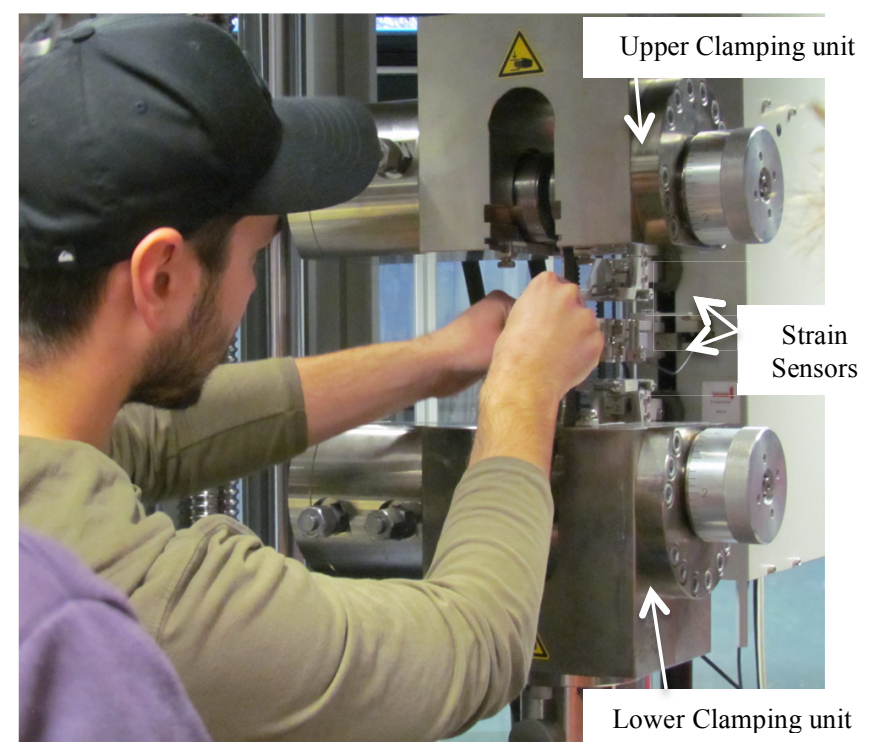

Figure 3. Student sets up the experiment by positioning the specimen 
example, the curves of the material are used in sheet metal forming simulations to design the required tools for a specific forming process.

Coming back to the miniLAB in mode 2 (a wider engineering context), the subject is introduced by providing a short overview on the website. In the case of material characterization, the importance of an appropriate set-up of a forming process is highlighted. Therefore, it is important to know the behavior of the material in use and this breaks down to testing the material in an experiment.

\section{Starting the miniLAB session}

If students find this mode appropriate, they can just enter some basic information about themselves and enroll. According to our experience, a number of four team members is ideal to have enough students for a fruitful exchange of ideas and not too many so that everybody is still able to actively participate. If a number of four students is reached, the time slot will be inaccessible, so additional time slots get offered to be selected.

Before the hands-on miniLABs session starts, students will be asked to do a self-directed preparation. This consists of the task to develop three individual learning questions on their own. We intend that this will additionally encourage students to prepare the selected subject on an appropriate level by themselves in advance. In this way, the students influence the lab session, which should foster a better motivation and identification with the subject. The learning questions will be discussed as active part of the lab session and there are no restrictions as to the scope of the question, so that also experienced students have the opportunity to expand their knowledge.

Starting with the actual hands-on lab session, students will be an integral part of the process of experimentation as shown in Figure 5. Here, a student, who attends one of the first miniLAB, investigates an extrusion process by carrying out real hands-on experiments.

Since the miniLABs offer the possibilities to students to just drop in and take part, the experiments itself are part of present research projects and therefore directly related to explicit questions in engineering science. This context will be explained to the students as a starting point. Afterwards the lab will be carried out interactively with enough time to discuss the prepared questions. During the first test run, we had a very vital discussion between the attendees and the tutor based on the questions carried out in advance. This was fostered by the fact that freshman as well as master students attended the minilab and they greatly exchanged information among each other.

Finishing a miniLAB session, students will be asked for their feedback to exchange experiences they gained, what they have learned and how this contributed to their overall picture of engineering professionals.

Concerning manufacturing technology at the Institute of Forming Technology and Lightweight Construction (IUL) of TU Dortmund University, several subjects are presently planned (each in mode 1 and 2). These are, for example, the investigation of material and component behavior using an optical measurement system or hardness testing of extruded components including both the extrusion process and the hardness test.

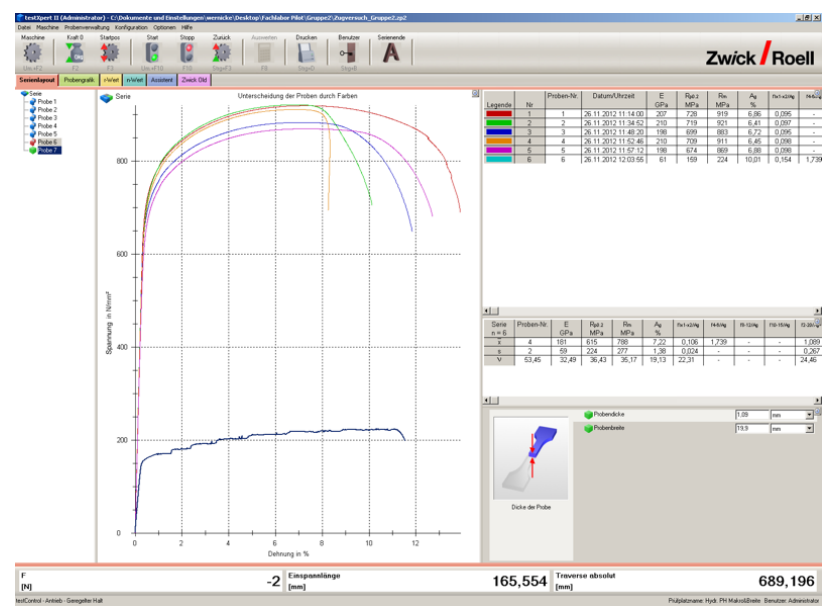

Figure 4. Data plot of different material tests

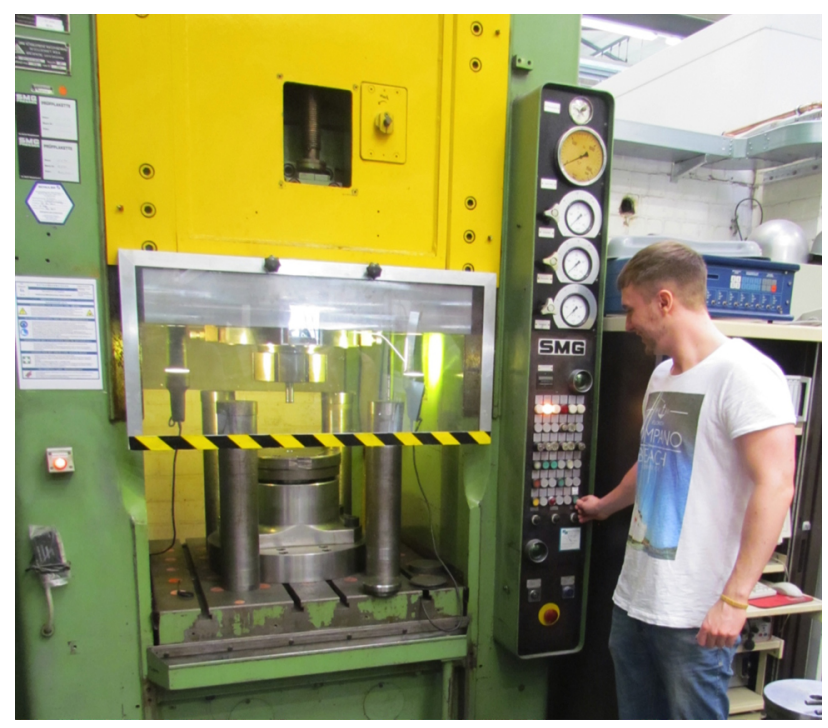

Figure 5. Student carrying out a supervised hands-on experiment

\section{CONClusion}

Based on our experience gained from several projects for laboratory learning in engineering education (e.g. [28] [29] [30] [31] [32]) and a long-standing experience with our own hands-on labs (e.g. [33]), we decided to try to lower the hurdles for freshman engineering students interested in experiments in our labs. The status quo is a concept that will be comprehensively improved and put into praxis step by step. Incorporating an accompanying feedback and evaluation process, we will provide the opportunity to influence and optimize the format of our hands-on miniLABs continuously.

\section{ACKNOWLEDGMENT}

The authors would like to thank all colleagues and student assistants who already contributed to the miniLABs. Of course special thanks go to our IT admin Georg and graphic designer Patrick for making the website as great as it is as well as to our colleagues of the research group LEED-MT "Laboratories in Engineering Education Manufacturing Technology”, which scientifically investigates on labs and the use of experiments in engineering education and its potential in contributing to the development of an understanding for its epistemological meaning 
as well as the engineering profession in general. Thank you to the Engineering Education Research Group (EERG) at TU Dortmund University, in which we are cultivating an intensive and constructive collaboration. Thank you to the Faculty of Mechanical Engineering of TU Dortmund University for providing the funding for this initiative.

\section{REFERENCES}

[1] D. Grasso and M. D. Burkins, "Beyond Technology: The Holistic Advantage," in Holistic Engineering Education, D. Grasso and M. D. Burkins, Eds. Springer, 2010, pp. 1-10. http://dx.doi.org/10.1007/978-1-4419-1393-7_1

[2] P. A. F. Martins, L. Kwiatkowski, V. Franzen, A. E. Tekkaya, and M. Kleiner, "Single point incremental forming of polymers," CIRP Annals -- Manufacturing Technology, vol. 58, no. 1, pp. 229-232, 2009.

[3] S. Chatti, M. Hermes, A. E. Tekkaya, and M. Kleiner, "The new TSS bending process: 3D bending of profiles with arbitrary crosssections," CIRP Annals -- Manufacturing Technology, vol. 59, no. 1, pp. 315-318, 2010.

[4] M. Hermes, "Neue Verfahren zum rollenbasierten 3D-Biegen von Profilen," Technische Universität Dortmund, Fakultät Maschinenbau, Institut für Umformtechnik und Leichtbau (IUL), 2011.

[5] M. E. Auer and A. Pester, "Toolkit for Distributed Online-Lab Grids," in Advances on remote laboratories and e-learning experiences, L. Gomes and J. Garc'ia-Zub'ia, Eds. Deusto Publicaciones, 2007, pp. 285-296.

[6] M. Bochicchio and A. Longo, "Hands-On Remote Labs: Collaborative Web Laboratories as a Case Study for IT Engineering Classes," IEEE Trans. Learn. Technol., vol. 2, no. 4, pp. 320-330, 2009. http://dx.doi.org/10.1109/TLT.2009.30

[7] L. Gomes and S. Bogosyan, "Current Trends in Remote Laboratories," IEEE Transactions on Industrial Electronics, vol. 56 , no. 12 , pp. 4744-4756, 2009. http://dx.doi.org/10.1109 /TIE.2009.2033293

[8] I. Gustavsson, K. Nilsson, J. Zackrisson, J. Garcia-Zubia, U. Hernandez-Jayo, A. Nafalski, Z. Nedic, O. Gol, J. Machotka, M. I. Pettersson, T. Lagö, and L. Hakansson, "On Objectives of Instructional Laboratories, Individual Assessment, and Use of Collaborative Remote Laboratories," IEEE Transactions on Learning Technologies, vol. 2, pp. 263-274, 2009. http://dx.doi.org/10.1109/TLT.2009.42

[9] H. Jack, "The 2011 State of Manufacturing Education," in Proceedings of the 2011 ASEE Annual Conference \& Exposition, 2011, p. AC 2011-1720.

[10] D. Magin and S. Kanapathipillai, "Engineering students' understanding of the role of experimentation," European Journal of Engineering Education, vol. 25, no. 4, pp. 351-358, 2000. http://dx.doi.org/10.1080/03043790050200395

[11] C. Pleul, C. Terkowsky, I. Jahnke, and A. E. Tekkaya, "Teleoperated laboratory experiments in engineering education -- The uniaxial tensile test for material characterization in forming technology," in Using Remote Labs in Education, J. Garc'iaZub'ia and R. G. Alves, Eds. Deusto Publicaciones, 2011, pp. 323347.

[12] W.-J. Shyr, "Internet-Based Laboratory Platform for Distance Learning in Engineering Education," International Journal of Engineering Education, vol. 25, no. 4, pp. 693-700, 2009.

[13] J. Ma and J. V Nickerson, "Hands-on, simulated, and remote laboratories: A comparative literature review," ACM Computing Surveys, vol. 38, no. 3, pp. 1-24, 2006. http://dx.doi.org/ $10.1145 / 1132960.1132961$

[14] J. E. Corter, S. K. Esche, C. Chassapis, J. Ma, and J. V Nickerson, "Process and learning outcomes from remotely-operated, simulated, and hands-on student laboratories," Computers \& Education, vol. 57, no. 3, pp. 2054-2067, 2011. http://dx.doi.org/10.1016/j.compedu.2011.04.009

[15] H.-G. Bruchmüller and A. Haug, Labordidaktik für Hochschulen - Eine Einführung zum Praxisorientierten Projekt-Labor. Leuchtturm-Verlag, 2001.

[16] R. Irish and P. E. Weiss, Engineering Communication. Oxford University Press, 2009.

[17] F. S. Becker, "Was heute von Elektroingenieuren verlangt wird -Markttrends. Erwartungen von Berufsanfängem, Erwartungen von Personalverantwortlichen, Karrieremechanismen," in Arbeitsmarkt
Elektrotechnik Informationstechnik 2007, 15. Auflag., J. Grüneberg and I.-G. Wenke, Eds. VDE-Verlag GmbH, 2007, pp. 13-32.

[18] B. Hanson, P. Culmer, J. Gallagher, K. Page, E. Read, A Weightman, and M. Levesley, "ReLOAD: Real Laboratories Operated at a Distance," IEEE Transactions on Learning Technologies, vol. 2, no. 4, pp. 331-341, 2009. http://dx.doi.org/ 10.1109/TLT.2009.35

[19] A. K. M. Azad, M. E. Auer, and V. J. Harward, "Internet accessible remote laboratories: scalable E-leaming tools for engineering and science disciplines." Engineering Science Reference, 2012.

[20] J. Leach, "Students' Understanding of the Nature of Science and its Influence on Labwork," in Teaching and Learning in the Science Laboratory, D. Psillos and H. Niedderer, Eds. Kluwer Academic Publishers, 2003, pp. 41-48. http://dx.doi.org/10.1007/ 0-306-48196-0_6

[21] D. A. Kolb, Experiential Learning. Prentice Hall, 1984.

[22] D. A. Kolb, R. E. Boyatzis, and C. Mainemelis, "Experiential Learning Theory: Previous Research and New Directions," in Perspectives on cognitive, learning, and thinking styles, R. J. Sternberg and L. F. Zhang, Eds. NJ: Lawrence Erlbaum, 2000.

[23] D. A. Kolb, "The Kolb Learning Style Inventory." 2005.

[24] J. Wildt, "The Shift from Teaching to Learning - Thesen zum Wandel der Lernkultur in modularisierten Studienstrukturen," in Unterwegs zu einem europäischen Bildungssystem, Fraktion Bündnis 90/Die Grünen im Landtag NRW, Ed. 2003.

[25] J. Wildt, "Vom Lehren zum Lernen - Zum Wandel der Lernkultur in modularisierten Studiengängen," in Neues Handbuch der Hochschullehre, B. Berendt, H.-P. Voss, and J. Wildt, Eds. Dr. Josef Raabe Verlags-GmbH, 2006, pp. 1-14.

[26] J. Biggs and C. Tang, Teaching for Quality Learning at University, 3rd ed. Mc Graw Hill, 2007.

[27] L. D. Feisel and A. J. Rosa, "The Role of the Laboratory in Undergraduate Engineering Education," Journal of Engineering Education, vol. 94, no. 1, pp. 121-130, 2005. http://dx.doi.org/ 10.1002/j.2168-9830.2005.tb00833.x

[28] C. Pleul, C. Terkowsky, I. Jahnke, and A. E. Tekkaya, "Platform for e-learning and tele-operative experimentation (PeTEX) -Holistically integrated laboratory experiments for manufacturing technology in engineering education," in Proceedings of SEFI Annual Conference, 2011, pp. 578-585.

[29] C. Pleul, C. Terkowsky, M. Hermes, and A. E. Tekkaya, "ProLab@Ing: Problem-basiertes Projekt-Labor in der ingenieurwissenschaftlichen Ausbildung," in Renaissance der Ingenieurpädagogik -- Entwicklungslinien im europäischen Raum, 2011, pp. 36-37.

[30] C. Pleul, S. Chatti, and A. E. Tekkaya, "Problem-based Laboratory Learning in Engineering Education (PBLL@EE)," in TeachINGLearnING.EU innovations, M. Petermann, S. Jeschke, A. E. Tekkaya, K. Müller, K. Schuster, and D. May, Eds. 2012, pp. $122-$ 123.

[31] D. May, C. Terkowsky, T. Haertel, and C. Pleul, "Using EPortfolios to support experiential learning and open the use of teleoperated laboratories for mobile devices," in Proceedings of International Conference of Remote Engineering \& Virtual Instrumentation (REV), 2012, pp. 172-180.

[32] C. Terkowsky, I. Jahnke, C. Pleul, D. May, T. Jungmann, and A. E. Tekkaya," "PeTEX@Work -- Designing Online Engineering Education," in CSCL at Work -- a conceptual framework, S. P. Goggins and I. Jahnke, Eds. Springer, 2012.

[33] C. Pleul, M. Hermes, C. Becker, C. Terkowsky, and A. E. Tekkaya, "Problembasiertes Projekt-Labor in der Ingenieurausbildung," in Renaissance der Ingenieurpädagogik -Entwicklungslinien im europäischen Raum, 2012, pp. 112-117.

\section{AUTHORS}

C. Pleul, A. Sadiki, M. Hermes, S. Chatti and A. E. Tekkaya are with TU Dortmund University, Institute of Forming Technology and Lightweight Construction (IUL), Dortmund, Germany

This article is an extended and modified version of a paper presented at the EDUCON2013 conference held at Technische Universität Berlin, Berlin, Germany from March 13-15, 2013. Received 15 May 2013. Published as resubmitted by the authors 21 May 2013. 